\title{
PENGARUH STRUKTUR MODAL DAN PERUBAHAN LABA TERHADAP NILAI PERUSAHAAN PERDAGANGAN ECERAN DI BURSA EFEK INDONESIA
}

\author{
Vargo Christian L. Tobing \\ Universitas Putera Batam \\ Email :vargo.tobing@gmail.com
}

\begin{abstract}
This research aims to see how the influence of capital structure and changes in earnings on the value of a company. The population in this study are retail trade sub-sector companies in the Indonesia Stock Exchange. Determination of the sample using purposive sampling method. The samples studied in this study were 9 companies. The results of the study concluded that the capital structure measured by the ratio of debt to equity ratio has no significant effect on firm value. Earnings changes have no significant effect on firm value, and simultaneously, capital structure and earnings changes have no significant effect of firm value
\end{abstract}

Keywords : Capital Structure, Changes in Profit, Firm Value

\begin{abstract}
Abstrak
Dilakukannya penelitian ini bertujuan melihat bagaimana pengaruh struktur modal dan perubahan laba pada nilai perusahaan. Populasi dalam penelitian ini adalah perusahaan sub sektor perdagangan eceran di Bursa Efek Indonesia. Penentuan sampel menggunakan metode purposive sampling. Sampel yang diteliti dalam penelitian ini sebanyak 9 perusahaan. hasil penelitian menyimpulkan bahwa struktur modal yang diukur dengan rasio debt to equity ratio berpengaruh tidak signifikan terhadap nilai perusahaan, perubahan laba berpengaruh tidak signifikan terhadap nilai perusahaan, dan secara simultan, struktur modal dan perubahan laba berpengaruh tidak singifikan terhadap nilai perusahaan.
\end{abstract}

Kata kunci: Struktur Modal, Perubahan Laba, Nilai Perusahaan

\section{PENDAHULUAN}

Nilai suatu perusahaan sangat tergantung dari keadaan keuangan perusahaan itu sendiri. Perusahaan harus mampu memiliki kondisi keuangan yang sehat agar perusahaan mempunyai nilai perusahaan yang tinggi. Keadaan keuangan yang sehat ini membuat perusahaan memiliki daya tarik di mata 
investor maupun kreditor yang berujung pada naiknya nilai perusahaan. Hal yang dinilai oleh investor yaitu kemampulabaan suatu perusahaan. Hal ini berkaitan dengan tujuan investor sendiri adalah untuk memperoleh keuntungan dari kegiatan investasi. Keuntungan akan diperoleh investor apabila perusahaan yang diinvestasikan memperoleh keuntungan. Maka tidaklah heran apabila perusahaan yang dapat memperoleh keuntungan yang tinggi merupakan incaran bagi para investor untuk menanamkan dananya untuk memperoleh keuntungan.

Modal yang besar akan mendorong laju pertumbuhan perusahaan, termasuk untuk memperoleh keuntungan. Tentunya banyak perusahaan yang terkendala dalam hal modal ini. Maka sumber pendanaan (modal) yang biasa digunakan oleh para pengusaha adalah dengan melakukan pinjaman. Rasio utang memiliki dua pengaruh yang berbeda bagi perusahaan tergantung dari kemampuan perusahaan dalam mengelola utang tersebut.

Porsi utang yang tinggi akan menjadi bumerang bagi perusahaan apabila perusahaan tidak mampu mengelola utang tersebut untuk kegiatan operasional perusahaan untuk mendapatkan keuntungan. Apabila keuntungan yang didapat perusahaan sedikit, maka perusahaan kemungkinan mengalami kesulitan dalam hal pelunasan utang tersebut. Sebaliknya, Apabila perusahaan dapat mengelola utang tersebut dengan baik sehingga menghasilkan keuntungan yang tinggi, sehingga tidak ada kesulitan bagi perusahaan untuk pelunasan utang.

Keuntungan adalah tujuan utama yang diharapkan oleh setiap perusahaan dalam menjalankan bisnisnya. Tanpa adanya laba, kegiatan produksi perusahaan akan terganggu dan jika kondisi ini terus berlangsung, akan mengakibatkan kebangkrutan bagi perusahaan.

Agar perusahaan dapat terus menghasilkan laba, maka diharapkan semua pihak di dalam perusahaan dapat bekerja secara maksimal untuk menghasilkan laba tersebut. Tentunya, perusahaan menginginkan laba yang tinggi. Maka dari itu, dibutuhkan modal yang besar yang harus dimiliki oleh entitas perusahaan

Tabel 1.1.

Nilai Perusahaan

\begin{tabular}{|l|l|l|l|l|}
\hline No & Emiten & $\mathbf{2 0 1 5}$ & $\mathbf{2 0 1 6}$ & $\mathbf{2 0 1 7}$ \\
\hline 1 & ACES & 153,28 & 177,77 & 204,69 \\
\hline 2 & AMRT & 116,80 & 127,51 & 124,85 \\
\hline 3 & CSAP & 294,82 & 348,32 & 376,33 \\
\hline 4 & ERAA & $1.105,31$ & $1.175,57$ & $1.278,16$ \\
\hline 5 & LPPF & 379,09 & 635,81 & 797,82 \\
\hline 6 & MAPI & $1.792,11$ & $1.929,83$ & $2.555,67$ \\
\hline 7 & MIDI & 255,24 & 310,55 & 320,18 \\
\hline 8 & RALS & 469,81 & 470,32 & 492,44 \\
\hline 9 & TELE & 395,42 & 446,30 & 464,67 \\
\hline
\end{tabular}

Nilai perusahaan mengalami kenaikan dan penurunan. Naik turunnya nilai perusahaan merupakan hal yang lumrah dalam kegiatan bisnis. Dikarenakan nilai perusahaan tersebut tergantung dari kemampuan perusahaan memperoleh laba. 
Vol.2, No. 2, Mei. 2019

\section{KERANGKA TEORITIS DAN PENGEMBANGAN HIPOTESIS}

\subsection{Struktur Modal (DER)}

Struktur modal dapat diartikan sebagai proporsi antara kewajiban panjang dan ekuitas atau modal perusahaan, baik itu saham preferen ataupun saham biasa yang dimiliki perusahaan. Kewajiban lancar tidak dimasukkan dalam struktur modal dikarenakan bukan bagian dari sumber pendanaan (Mardiyanto, 2008, p. 258).

Menurut (Martono \& Harjito, 2013) struktur modal adalah perbandingan atau imbangan pendanaan jangka panjang perusahaan yan ditunjukkan oleh perbandingan hutang jangka panjang terhadap modal sendiri. Menurut (Sjahrial, 2010) struktur modal merupakan perimbangan antara penggunaan modal pinjaman yang terdiri dari utang jangka pendek yang bersifat permanen, utang jangka panjang dengan modal sendiri yang terdiri dari saham preferen dan saham biasa. Sedangkan menurut (Margaretha, 2007) Struktur modal menggambarkan pembiayaan permanen perusahaan yang terdiri dari hutang jangka panjang dan modal sendiri.

\subsection{Perubahan Laba}

Laba merupakan hasil akhir yang ingin didapat dalam satu periode kegiatan usaha. Laba juga menjadi indikator bagi investor maupun kreditor dalam pengambilan keputusan ekonomik. Perusahaan tentu mengharapkan kenaikan laba setiap tahunnya. Kenaikan laba tentu menjadi modal utama bagi perusahaan untuk menarik minat investor maupun kreditor. Investor akan menginvestasikan dananya kepada perusahan apabila perusahaan tersebut mampu menghasilkan laba. Dengan begitu, maka investor juga akan memperoleh imbalan hasil atas penanaman modal yang telah dilakukan, dan imbalan yang diterima oleh investor dapat berupa dividen.

\subsection{Nilai Perusahaan}

Hal yang menjadi fokus perusahaan yaitu menaikkan nilai perusahaan, nilai perusahaan dipakai sebagai indikator berhasil atau tidak berhasilnya perusahaan, Naiknya nilai perusahaan memungkinkan juga naiknya kemakmuran pemilik saham. Nilai suatu perusahaan itu sendiri dapat dilihat dari nilai saham dari perusahaan yang bersangkutan (Martono. \& Harjito, 2010). Sedangkan menurut (Sartono, 2012), nilai perusahaan bertujuan untuk meningkatkan kesejahteraan para investor sebagai pemilik saham. Semakin naiknya harga saham, maka keuntungan investor sebagai pemilik saham juga akan mengalami kenaikan.

\subsection{Kerangka Penelitian}

Adapun rancangan yang digunakan dalam penelitian ini yaitu: 


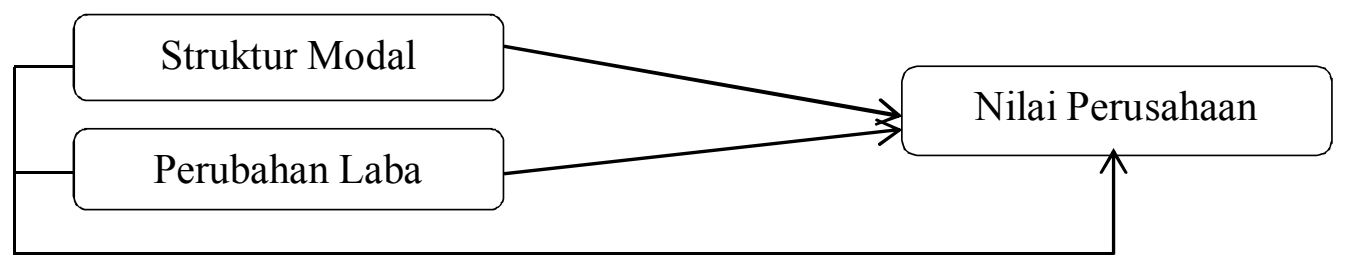

\section{Gambar 2.1 \\ Kerangka Penelitian}

\subsection{Hipotesis Penelitian}

Hipotesis yang diajukan yaitu:

1. Struktur modal perusahaan yang diukur dengan DER mempunyai pengaruh yang signifikan terhadap nilai perusahaan

2. Perubahan laba memiliki pengaruh yang signifikan terhadap nilai perusahaan

3. Struktur modal yang dinilai dengan DER dan perubahan laba secara simultan memiliki pengaruh yang signifikan terhadap nilai perusahaan.

\section{METODE RISET}

Populasi merupakan sekelompok orang, kejadian, sesuatu yang mempunyai karakteristik tertentu. Populasi merupakan wilayah generalisasi yang terdiri dari objek atau subjek yang menjadi kuantitas dan karakteristik tertentu yang ditetapkan oleh peneliti untuk dipelajari dan kemudian ditarik kesimpulannya (Rumengan, 2013).

Jenis penelitian ini yaitu kausalitas yang memiliki tujuan mendeskripsikan keterkaitan antara dua variabel atau lebih. Penelitian ini memiliki tujuan untuk melihat pengaruh struktur modal dan perubahan laba terhadap nilai suatu perusahaan.

Populasi dalam penelitian ini merupakan perusahaan yang bergerak di sub sektor pedagangan eceran yang terdaftar di Bursa Efek Indonesia. Sampel dalam penelitian ini ditentukan menggunakan metode purposive sampling method. Dengan jumlah sampel adalah sebanyak 9 perusahaan.

\section{ANALISIS DATA DAN PEMBAHASAN}

\subsection{Uji Asumsi Klasik \\ 1. Uji Normalitas}


Tabel 4.1

Hasil uji normalitas

One-Sample Kolmogorov-Smirnov Test

\begin{tabular}{|ll|l|}
\hline & & $\begin{array}{l}\text { Standardized } \\
\text { Residual }\end{array}$ \\
\hline N & & 27 \\
Normal Parameters & & 0.0000000 \\
& Mean & 0.96076892 \\
& Std. Deviation & 0.117 \\
Most Extreme Differences & Absolute & 0.117 \\
& Positive & -0.075 \\
Kolmogorov-Smirnov Z & Negative & 0.609 \\
Asymp. Sig. (2-tailed) & & 0.852 \\
\hline
\end{tabular}

Nilai Asymp. Sig (2-tailed) sebesar 0,852. score signifikan ini $>0.05$. Dapat dikatakan bahwa data data penelitian ini telah lulus uji normalitas.

\section{Uji Multikolinearitas}

Tabel 4.2

Hasil uji multikolinearitas

Coefficients $^{\mathrm{a}}$

\begin{tabular}{|ll|l|l|}
\hline \multirow{2}{*}{ Model } & \multicolumn{3}{|l|}{ Collinearity Statistics } \\
\cline { 3 - 4 } & Tolerance & VIF \\
\hline \multirow{2}{*}{1} & Ln_x1 & 0.883 & 1.132 \\
& Ln_x2 & 0.883 & 1.132 \\
\hline
\end{tabular}

Terlihat bahwa nilai VIF struktur modal (Ln_x1) dan perubahan laba (Ln_x2) sebesar 1,132. Nilai VIF ini $<10$. Dari hasil tersebut, sehingga dapat ditarik suatu kesimpulan jika data penelitian ini tidak terjadi masalah multikolinearitas.

\section{Pengujian Heteroskedastisitas}

Gambar scatter plot sebagai berikut:

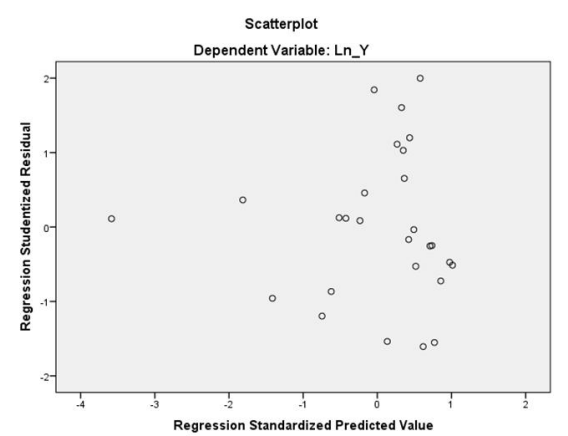

Gambar 4.1 
Vol.2, No. 2, Mei. 2019

\section{Scatter plot}

Berdasarkan gambar di atas, terlihat jika pola pada gambar tersebut menyebar di atas dan di bawah angka nol dan tidak membentuk pola atau gambar yang jelas, maka dapat ditarik kesimpulan tidak ada gejala heteroskedastisitas.

\section{Uji Autokorelasi}

Hasil uji autokorelasi sebagai berikut:

Tabel 4.3

Hasil uji autokorelasi Model Summary ${ }^{b}$

\begin{tabular}{|l|l|l|l|l|l|}
\hline Model & R & R Square & Adjusted R Square & $\begin{array}{l}\text { Std. Error of the } \\
\text { Estimate }\end{array}$ & $\begin{array}{l}\text { Durbin- } \\
\text { Watson }\end{array}$ \\
\hline 1 & $0.098^{\mathrm{a}}$ & 0.010 & -0.073 & 0.88339 & 1.594 \\
\hline
\end{tabular}

Durbin Watson memiliki nilai 1.594. score dl yaitu 1.1624 , dan nilai du yaitu 1.6510. Atau $1.1624<1,594<2.349$. Dari hasil persamaan tersebut, maka diambil kesimpulan tidak ada masalah autokorelasi.

\subsection{Uji Hipotesis}

\section{Uji Hipotesis Parsial}

Tabel 4.4

Hasil Uji Parsial

Coefficients $^{\mathrm{a}}$

\begin{tabular}{|ll|l|l|l|l|l|}
\hline \multirow{2}{*}{ Model } & \multicolumn{2}{|l|}{ Unstandardized Coefficients } & $\begin{array}{l}\text { Standardized } \\
\text { Coefficients }\end{array}$ & & \multirow{2}{*}{ Sig. } \\
\cline { 2 - 4 } & & B & Std. Error & Beta & & \\
\hline \multirow{2}{*}{1} & (Constant) & 5.642 & 1.273 & & 4.434 & 0.000 \\
& Ln_x1 & 0.051 & 0.136 & 0.080 & 0.372 & 0.713 \\
& Ln_x2 & 0.024 & 0.152 & 0.034 & 0.159 & 0.875 \\
\hline
\end{tabular}

\section{Struktur modal yang diukur dengan DER terhadap nilai perusahaan}

Score signifikansi struktur modal (Ln_X1) yang diukur dengan DER memiliki score sebesar 0.713. nilai signifikansi ini $>$ sig. 0.05. Dapat disimpulkan jika struktur modal yang diukur dengan DER memiliki pengaruh yang tidak signifikan terhadap nilai perusahaan.

\section{Perubahan laba terhadap nilai perusahaan}

Score signifikansi perubahan laba (Ln_X2) memiliki nilai sebesar 0.875 . Nilai signifikansi ini $>$ sig. 0.05. sehingga dapat disimpulkan bahwa perubahan laba berpengaruh tidak signifikan terhadap nilai perusahaan. 


\section{Uji F (Hipotesis Simultan)}

Tabel 4.5

Uji F (Uji Simultan)

ANOVA ${ }^{\mathrm{a}}$

\begin{tabular}{|rl|r|r|r|r|r|}
\hline \multicolumn{1}{|c|}{ Model } & Sum of Squares & df & Mean Square & F & Sig. \\
\hline \multirow{3}{*}{1} & Regression & 0.180 & 2 & 0.090 & 0.116 & $0.891^{\mathrm{b}}$ \\
& Residual & 18.729 & 24 & 0.780 & & \\
& Total & 18.909 & 26 & & & \\
\hline
\end{tabular}

\section{Struktur modal (DER) dan perubahan laba secara simultan terhadap nilai perusahaan.}

Score signifikansi sebesar 0.891. nilai signifikansi ini $>$ sig. 0.05. sehingga diambil kesimpulkan bahwa struktur (DER) modal dan perubahan laba secara simultan berpengaruh tidak signifikan terhadap nilai perusahaan.

\section{Analisis Determinasi}

Tabel 4.6

\section{Analisis koefisien determinasi}

\begin{tabular}{|l|l|l|l|l|}
\multicolumn{5}{c|}{ Model Summary $^{\mathbf{b}}$} \\
\hline Model & R & R Square & $\begin{array}{l}\text { Adjusted } \\
\text { Square }\end{array}$ & $\begin{array}{l}\text { R } \\
\text { Std. Error of the } \\
\text { Estimate }\end{array}$ \\
\hline 1 & $0.098^{\mathrm{a}}$ & 0.010 & -0.073 & 0.88339 \\
\hline
\end{tabular}

$R$ square bernilai 0.010 atau $1 \%$. Hal ini berarti struktur modal dan perubahan laba memberikan pengaruh terhadap nilai perusahaan dengan besaran $1 \%$. dan selebihnya dengan besaran $99 \%$ dipengaruhi oleh variabel yang tidak turut diuji dalam model penelitian ini.

\subsection{Pembahasan}

1. Struktur modal terhadap nilai perusahaan

Penyebab tidak pengaruhnya struktur modal secara signifikan terhadap nilai perusahaan kemungkinan terjadi dikarenakan utang yang menjadi sumber pendanaan perusahaan tidak digunakan secara seefektif mungkin, dan disebabkan juga oleh pengelolaan perusahaan dalam menghasilkan penjualan yang tidak sesuai dengan harapan. Kewajiban perusahaan mengalami pertambahan untuk mendanai kegiatan perusahaan, akan tetapi tidak didukung oleh kemampuan perusahaan dalam menghasilkan keuntungan yang tinggi. Kondisi seperti ini menyebabkan perusahaan kesulitan dalam melakukan pembayaran utang sehingga memperburuk kemampuan perusahaan dalam pengelolaan utang. Struktur modal perusahaan tidak bagus, sehingga pendanaan yang bersumber dari utang memberikan pengaruh yang jelek terhadap keuangan perusahaan. 
2. Perubahan laba pada nilai perusahaan

Perubahan laba tidak pengaruh secara signifikan terhadap nilai suatu entitas perusahaan. Kondisi ini dapat disebabkan karena manajemen perusahaan dalam menghasilkan keuntungan yang tidak maksimal. Baik sumber daya, maupun kewajiban perusahaan tidak diolah seefektif mungkin untuk memperoleh keuntungan. Perubahan laba yang kecil ini tidak memberikan dampak positif yang cukup signifikan terhadap naiknya nilai yang dimiliki oleh perusahaan.

3. Struktur Modal dan Perubahan laba pada nilai perusahaan

Struktur modal perusahaan yang diukur dengan Debt to Equity Ratio (DER), yang mana struktur modal ini bersumber dari utang untuk dijadikan modal perusahaan dalam kegiatan operasional perusahaan. Utang yang dimiliki dapat digunakan untuk mengembangkan perusahaan. Dengan utang yang besar dan diolah dengan baik, maka akan dapat menaikkan nilai perusaahaan itu sendiri.

Laba yang diperoleh perusahaan tidak terlepas dari kemampuan perusahaan dalam menjalankan kegiatan operasional perusahaan dengan mengoptimalkan seluruh sumber daya ekonomi yang dimiliki. Laba yang tinggi yang diperoleh perusahaan akan menaikkan nilai perusahaan itu sendiri, dikarenakan para investor maupun calon investor akan sangat tertarik pada kemampuan perusahaan dalam menghasilkan laba.

Dalam penelitian ini, struktur modal dan perubahan laba tidak memberikan pengaruh yang signifikan terhadap nilai perusahaan. Tidak berpengaruhnya kedua variabel di atas, dapat disebabkan pengelolaan utang yang tidak efektif, sehingga utang yang dimiliki tidak dapat memberikan keuntungan yang besar, sehingga kinerja keuangan perusahaan terlihat tidak menarik. kondisi keuangan seperti ini tidak akan memberikan pengaruh signifikan terhadap naiknya nilai perusahaan.

\section{SIMPULAN DAN SARAN}

Adapun kesimpulan yang dapat ditarik dalam penelitian ini adalah:

1. Rasio DER yang digunakan untuk mengukur struktur modal memiliki pengaruh yang tidak sinifikan terhadap nilai perusahaan

2. Perubahan laba memiliki pengaruh yang tidak signifikan terhadap nilai perusahaan

3. Struktur modal dan perubahan laba memberikan pengaruh sebesar $1 \%$ terhadap nilai perusahaan

Adapun saran yang di berikan untuk penelitian selanjutnya adalah :

1. Diharapkan penelitian ini menjadi bahan referensi bagi pihak terkait dalam pengambilan keputusan ekonomik

2. Walaupun struktur modal yang dinilai dengan rasio DER dan perubahan laba tidak berpengaruh signifikan terhadap nilai perusahaan. Diharapkan perusahaan tetap memperhatikan kedua variable tersebut. Sehingga dapat meningkatkan kinerja keuangan perusahaan. 
Vol.2, No. 2, Mei. 2019

\section{DAFTAR PUSTAKA}

Mardiyanto, H. (2008). Inti Sari Manajemen Keuangan, Teori, Soal dan Jawaban. Jakarta: Grasindo.

Margaretha, F. (2007). Manajemen Keuangan. Jakarta: Grasindo.

Martono., \& Harjito, A. (2013). Manajemen Keuangan (3rd ed). Yogyakarta: Ekonisia.

Martono., \& Harjito, D. A. (2010). Manajemen Keuangan. Yogyakarta: Ekonisia.

Rumengan, J. (2013). Metodologi Penelitian. Bandung: Ciptapustaka Media Perintis.

Sartono, A. (2012). Manajemen Keuangan Teori dan Aplikasi. Yogyakarta: BPFE.

Sjahrial, D. (2010). Manajemen Keuangan (4th ed). Jakarta: Mitra Wacana Media. 